\title{
Assessment of the state of pharmacovigilance in the South-South zone of Nigeria using WHO pharmacovigilance indicators
}

\author{
Abimbola O. Opadeyi ${ }^{1,2^{*}}$ (D), Annie Fourrier-Réglat ${ }^{3,4,5}$ and Ambrose O. Isah ${ }^{1,2,6}$
}

\begin{abstract}
Background: WHO pharmacovigilance indicators have been recommended as a useful tool towards improving pharmacovigilance activities. Nigeria with a myriad of medicines related issues is encouraging the growth of pharmacovigilance at peripheral centres. This study evaluated the status of pharmacovigilance in tertiary hospitals in the South-South zone of Nigeria with a view towards improving the pharmacovigilance system in the zone.

Methods: A cross-sectional descriptive survey was conducted in six randomly selected tertiary hospitals in the South-South zone of the country. The data was collected using the WHO core pharmacovigilance indicators. The language of assessment was phrased and adapted in this study for use in a tertiary hospital setting. Data is presented quantitatively and qualitatively.

Results: A total of six hospitals were visited and all institutions had a pharmacovigilance centre, only three could however be described as functional or partially functional. Only one centre had a financial provision for pharmacovigilance activities. Of note was the absence of the national adverse drug reaction reporting form in one of the hospitals. The number of adverse drug reaction reports found in the databases of the centres ranged from none to 26 for the previous year and only one centre had fully committed their reports to the National Pharmacovigilance Centre. There were few documented medicines related admissions ranging from 0.0985/1000 to $1.67 / 1000$ and poor documentation of pharmacovigilance activities characterised all centres.

Conclusion: This study has shown an urgent need to strengthen the pharmacovigilance systems in the SouthSouth zone of Nigeria. Improvement in medical record documentation as well as increased institutionalization of pharmacovigilance may be the first steps to improve pharmacovigilance activities in the tertiary hospitals.
\end{abstract}

Keywords: Pharmacovigilance, Adverse drug reaction reporting, Nigeria, Tertiary hospitals

\section{Background}

Pharmacovigilance in Nigeria commenced in the late 80s and early 90 s initially in a tertiary hospital with some preparatory activities at the national level prior to its admission into the WHO program for international drug monitoring (PIDM) in 2004 [1, 2]. It has sustained its activities through active training of healthcare workers,

\footnotetext{
* Correspondence: felabimbola@yahoo.com

'Department of Clinical Pharmacology and Therapeutics, University of Benin, Benin-City, Edo State, Nigeria

2Department of Medicine, University of Benin Teaching Hospital, Benin-City, Nigeria

Full list of author information is available at the end of the article
}

sensitisation campaigns using print and electronic media about medicine safety issues to health care workers and the public [3]. It has also carried out active surveillance through the cohort event monitoring on adverse reactions to antimalarials (artemisinin-based combination therapy) [4]. There has also been the introduction of electronic devices to reduce substandard and falsified medical products which is a major contributor to adverse drug reactions in our setting.

The growth of pharmacovigilance in Nigeria has been propelled by a number of factors including the establishment of the regulatory agency (National Agency for Food

(c) The Author(s). 2018 Open Access This article is distributed under the terms of the Creative Commons Attribution 4.0 International License (http://creativecommons.org/licenses/by/4.0/), which permits unrestricted use, distribution, and reproduction in any medium, provided you give appropriate credit to the original author(s) and the source, provide a link to the Creative Commons license, and indicate if changes were made. The Creative Commons Public Domain Dedication waiver (http://creativecommons.org/publicdomain/zero/1.0/) applies to the data made available in this article, unless otherwise stated. 
and Drug Administration and Control - NAFDAC) by Decree 15 of 1993 (as amended) now cited as Act Cap N1 laws of the Federal Republic of Nigeria 2004, the formulation of the Nigerian National Drug Policy in 2005 [5]. This was further clarified by the introduction of the Nigerian pharmacovigilance policy document in 2012 firmly positing drug safety in national discussion [6]. The actualization of some of these goals has recorded significant progress with the formation of the zonal centres to cover the six geo-political zones in the country in 2012 [7].

Pharmacovigilance has a wide scope with increasing product concerns. The main focus in the Nigeria context has been on adverse drug reactions, substandard and falsified medical products $[3,8-10]$. Other areas yet to be fully addressed include medication errors [11], lack of effectiveness reports, acute and chronic poisoning $[12,13]$, assessing drug related mortality as well as abuse and misuse of medicines [3, 9]. The determination of the burden of these various problems has been poor as the major challenge to the growth of pharmacovigilance in Nigeria has been that of underreporting as seen worldwide [14-16].

Reporting of drug safety concerns by health-workers in Nigeria is voluntary and the reasons for under-reporting are partly due to fear of litigation, poor understanding of the subject matter, feeling that the "known" Adverse Drug Reactions (ADRs) need not be reported, time constraints and cumbersome reporting processes [17-21]. Lack of appropriate structures and deficient processes at the institutional level may also contribute to the poor reporting rate as found in some studies [17, 21-23].

WHO advocates regional centres as an effective way of enhancing pharmacovigilance activities [24] as observed in some areas of the world where this has been found to improve the number and quality of reports $[25,26]$.

The aims of the creation of the zonal centres was to decentralize the activities of the National Pharmacovigilance Centre (NPC), e.g. distribution of ADR forms and collection of the Individual Case Safety Reports (ICSRs) from reporters and perform preliminary evaluation with prompt reporting, also transmission of acknowledgements and feedback information to the reporters and dissemination of information from the national centre to the patients and health care workers. Furthermore, they were created to monitor the progress of pharmacovigilance activities at institutional levels as well as support the training and capacity building for pharmacovigilance in the areas of their jurisdiction [6]. These measures would further increase awareness about pharmacovigilance and instil a sense of ownership among the stakeholders regarding pharmacovigilance activities as well as bring closer to the reporters a centre close to their practice.
Currently, the assessment of pharmacovigilance had been largely done at the national level using various tools including evaluating the attainment of minimum requirements for a national centre with interviews of focal persons [27], and recently the use of the Indicator based Pharmacovigilance Assessment Tool (IPAT) indicators [28]. The more recent introduction of the WHO pharmacovigilance indicators provides an opportunity to assess pharmacovigilance activities at the national centres [29]. These indicators targeted at the national centres perform self-evaluation and also identify areas that require intervention. This approach may be applicable to zonal centres and its components which feed data to the national centres. It may also be most appropriate to identify problems at sub-national levels requiring attention [30].

The status of the pharmacovigilance system in the tertiary centres is presently unknown as the WHO indicators and related metrics for evaluating these centres have just been recently released [29] and there is little or no data on the effectiveness and functionality of these centres at this time. Furthermore, the involvement of these centres in this self-appraisal will further facilitate their participation in measures to remedy identified deficiencies with a view towards improving the quantity and quality of adverse drug reaction reports and other areas in pharmacovigilance. This study intends to assess the status of pharmacovigilance structure, processes, outcomes and impact in the South-South zone of Nigeria using the newly introduced WHO pharmacovigilance indicators.

\section{Methods}

\section{Study setting and design}

This study was carried out in the South-South Zone of Nigeria which is located in the coastal region of Nigeria. It comprises six states namely Akwa-Ibom, Bayelsa, Cross Rivers, Delta, Edo and Rivers with a population of 21,014, 655 million persons (Nigeria national census 2006). Health care professionals in all tiers of hospitals in this zone could send their reports either directly or through the zonal pharmacovigilance centre for onward transmission to the national centre. The South-South zonal pharmacovigilance centre is domiciled in the University of Benin Teaching Hospital, a tertiary hospital for research and learning.

In Nigeria, heath care is delivered at three levels: primary, secondary and tertiary. Tertiary care hospitals provide the highest level of care and serve as referral centres for the secondary and primary centres. Furthermore, there are three main types of tertiary centres. Firstly: the teaching hospitals, which provide teaching (to most cadres in the health professions at undergraduate and postgraduate levels for medical, nursing, pharmacy students etc.) as 
well as for research and health care services. Secondly: Federal Medical Centres which are mainly for health care services as well as providing residency training in some departments and lastly the specialty hospitals which focuses on particular disease entities of public health importance such as neuro-psychiatric hospitals, orthopaedic hospitals and ophthalmic hospitals among others.

This study was directed at the teaching hospitals because they provide the widest access to all patients with an inclusiveness of all cadres of health care workers. In the South-South zone there are eight teaching hospitals, seven are government owned, and one privately owned.

Eligibility criteria: teaching hospitals were used to ensure inclusiveness of all clinical disciplines and staff complement. All six states in the zone were represented by a teaching hospital. An institutional approval was required from the Chief Medical Director / Management prior to inclusion in the study. The study was subsequently carried out in 6 tertiary health institutions selected through simple random sampling in the various states namely:

- University of Benin Teaching Hospital Benin-City, Edo State, (UBTH).

- Delta State University Teaching Hospital Oghara, Delta State, (DELSUTH).

- Niger Delta University Teaching Hospital Okolobri, Bayelsa State, (NDUTH).

- University of Port Harcourt Teaching Hospital, Port Harcourt, Rivers State, (UPTH).

- University of Uyo Teaching Hospital, Uyo, AkwaIbom State, (UUTH).

- University of Calabar Teaching Hospital, Calabar Cross-River State, (UCTH).

Prior to visiting the study sites for data collection, ethical approval was obtained from the research and ethics committee of each of the selected tertiary hospitals. Furthermore, the heads of the institution were contacted for approval and access to the pertinent data. The focal persons in charge of pharmacovigilance in the institution provided answers for the indicator assessments.

\section{Data collection}

The data were obtained using a modified WHO data collection form for pharmacovigilance indicators [29] by one of the researchers through interviews of the focal person for pharmacovigilance or the pharmacovigilance committee. The components of this form included the background information, structural indicators, process indicators, outcome/impact indicators. The phrasing of the assessment questions was adapted to address the tertiary hospital setting (Additional file 1).
The background information collected characteristics of the hospitals: teaching hospital staff strength, i.e. number of post registration health professionals in different categories: doctors, nurses, pharmacists, specialist disposition, average out-patient attendance over the last year, total number of beds in the hospital.

The structural indicators assessed the existence of key pharmacovigilance structures, systems and mechanisms in any of the settings studies. It details the basic infrastructure needed to enable good pharmacovigilance activities. It assesses the enabling environment needed for pharmacovigilance activities.

The process indicators assessed the degree of pharmacovigilance activities in the various centres. It focussed on the processes that describe the collection, collation, analysis and evaluation of ADR reports. The factors influencing these processes were also considered. These measures were assessed directly or indirectly.

The outcome/impact indicators measure the extent of realization of the pharmacovigilance objectives. The hospital records used in assessing the outcome/impact indicators include admission and discharge registers, death registers, International coding of disease registers where available. Other requested details were: the total number of outpatient visits in the previous year, the morbidity and mortality statistics of each institution for the previous year (to include the disease statistics of admitted and deceased persons). Furthermore, to compute the duration of hospital stay, the crude estimates of the duration of admission of patients with serious adverse reactions who were hospitalised was calculated from the adverse drug reaction reports obtained for the previous year.

\section{Data analysis}

Analysis was both qualitative and quantitative. All hospitals participating in the study were described according to each indicator. The core Structural indicators are qualitative indicators with categorical data analysed descriptively. The presence or absence of the parameter measured was described for each institution.

Analysis of the core Process and Outcome Indicators are quantitative indicators reflecting rates of reports and actual numbers. They were calculated using frequencies and absolute numbers as dictated by the indicator. The data was analysed with descriptive statistics using Microsoft excel 2007.

\section{Results}

All six institutions were visited and the focal Pharmacovigilance persons or committees interviewed following a meeting with the various heads of the institutions. The teaching hospitals in this study are all government owned and serve as referral centres to the primary and 
secondary tier hospitals. However, they are of varying sizes in terms of bed and staff complement. The demographic characteristics of the institutions at the commencement of the study late January to mid-March 2016 were as follows (Table 1).

\section{Core structural indicators}

Responses were obtained from the interviewed personnel for the assessment questions of the 10 structural indicators for all the institutions studied. Three of the 6 institutions had a standardised functional accommodation for pharmacovigilance activities while 1 had non functional rooms and 2 had none. Only one hospital had regular financial provisions for pharmacovigilance. The secretariat in 4 centres had a full time staff to carry out pharmacovigilance activity while 2 had part time staff. Of note was the availability of an institutionalized ADR reporting form in one of the six centres (DELSUTH) while a centre neither had copies of the national nor local forms available. There were no standard forms available which addressed the subset of assessment questions covering the scope of pharmacovigilance in all of the centers (Table 2).

\section{Core process indicators}

The absolute number of ADR reports received among the 6 hospitals in the previous year ranged from 0 to 26, two hospitals had no reports for the previous year 2015 . Furthermore, the total number of reports in the local database ranged from 0 to 831. Cohort event monitoring of antimalarials (artemisinin-based combination therapy) was carried out and completed in UBTH in the five years preceding the analysis as a form of active surveillance. There were limited numbers of reports on ADRs, medication errors, lack of therapeutic effectiveness etc. in most of the centers. Documentation of feedback and causality assessment carried out on reports in the centers was equally poor in this study (Table 3 ).

\section{Core outcome/impact indicators}

Unusual reports regarding the development of frequent micturition following use of amlodipine besylate was observed in one of the centers and is being evaluated (Table 4). The number of medicine-related hospital admissions per 1000 admissions ranged from $0.00958 / 1000$ to $1.67 / 1000$ and there were no documentations of medicine related deaths in the death registers in the various hospitals. The documentation of pertinent data was inadequate, rendering calculation of other outcome/ impact pharmacovigilance indicators in the institutions difficult (Table 4).

\section{Discussion}

This is the first published study evaluating the practice of pharmacovigilance in tertiary hospitals of the South-South zone of Nigeria using the WHO indicators. The study has highlighted the strengths and weaknesses of the pharmacovigilance sub-healthcare system in general.

The study revealed that structures were gradually being put in place and there was a general acceptance of the need for pharmacovigilance in all the institutions visited despite institutional challenges. The availability of the newly developed Nigerian national pharmacovigilance policy in some of the centers is a testament to the will of the Nigerian government to institutionalize patient safety through good pharmacovigilance practice.

It was observed that the UBTH performed better than the other hospitals within the zone, this was ascribed to the activities of the pharmacovigilance team and system that started off in the early 90s [2] and has been largely sustained by the commitment of the pharmacovigilance committee, staff and management. It was also observed that despite DELSUTH and NDUTH being relatively smaller hospitals in terms of bed complement, they still performed better than some larger hospitals. This suggests that interest of the key stakeholders in the pharmacovigilance program is needed to sustain the development of the pharmacovigilance system.

Table 1 Characteristics of the tertiary teaching hospitals in the South-South Zone ${ }^{a}$

\begin{tabular}{|c|c|c|c|c|c|c|}
\hline Characteristic & UCTH & UUTH & UPTH & NDUTH & DELSUTH & UBTH \\
\hline Number of beds & 610 & 499 & 782 & 148 & 250 & 701 \\
\hline Approximate number of health care workers (post registration) & 1141 & 739 & 1028 & 253 & 532 & 1219 \\
\hline Consultant Clinicians & 146 & 86 & 179 & 85 & 65 & 200 \\
\hline Doctors & 359 & 124 & 210 & 53 & 150 & 335 \\
\hline Nurses & 580 & 417 & 600 & 105 & 300 & 660 \\
\hline Pharmacists & 56 & 19 & 39 & 10 & 17 & 24 \\
\hline Out-patient attendance in the previous year (2015) & 81,624 & 114,523 & 114,277 & 32,906 & 22,540 & 179,255 \\
\hline Number of in-patient hospital admissions (2015) & 7171 & 9679 & 10,145 & 2548 & No data & 11,324 \\
\hline
\end{tabular}

a UBTH University of Benin Teaching Hospital Benin-City, Edo State, UCTH University of Calabar Teaching Hospital, Calabar Cross-River State. UPTH University of Port Harcourt Teaching Hospital, Port Harcourt, Rivers State, UUTH University of Uyo Teaching Hospital, Uyo, Akwa- Ibom State. DELSUTH Delta State University Teaching Hospital Oghara, Delta State, NDUTH Niger Delta University Teaching Hospital Okolobri, Bayelsa State 
Table 2 Analysis of WHO Core Pharmacovigilance Structural Indicators of the six tertiary hospitals in the South-South zone of Nigeria

\begin{tabular}{|c|c|c|c|c|c|c|c|c|}
\hline Indicator Item & Assessment & UCTH & UUTH & UPTH & NDUTH & DELSUTH & UBTH & $\begin{array}{l}\text { Hospitals } \\
\text { with positive } \\
\text { answers (n) }\end{array}$ \\
\hline CST1 & $\begin{array}{l}\text { Presence of pharmacovigilance centre/department / } \\
\text { unit with a standard accommodation. }\end{array}$ & Yes & No & No & No & Yes & Yes & 3 \\
\hline CST2 & $\begin{array}{l}\text { Availability of a copy of the Nigerian pharmacovigilance } \\
\text { policy }\end{array}$ & Yes & No & No & Yes & Yes & Yes & 4 \\
\hline CST3 & Presence of Institutional Drug Therapeutic Committee & Yes & No & No & Yes & Yes & Yes & 4 \\
\hline CST4 & $\begin{array}{l}\text { Availability of regular financial provision for the } \\
\text { pharmacovigilance Centre. }\end{array}$ & No & No & No & No & No & Yes & 1 \\
\hline CST5 & $\begin{array}{l}\text { Availability of human resources to carry out functions } \\
\text { of Pharmacovigilance Centre. }\end{array}$ & Yes & Yes & Yes & Yes & Yes & Yes & 6 \\
\hline \multirow[t]{2}{*}{ CST6 } & $\begin{array}{l}\text { Availability of standard ADR reporting form in the } \\
\text { institution. }\end{array}$ & Yes & Yes & No & Yes & Yes & Yes & 5 \\
\hline & $\begin{array}{l}\text { CP6a-e: Availability of relevant fields in standard ADR } \\
\text { reporting form for a) medication error, b) counterfeit/ } \\
\text { substandard medicines, c) therapeutic ineffectiveness, d) } \\
\text { suspected misuse, abuse, dependence on medicines, e) } \\
\text { general public. }\end{array}$ & No & No & No & No & No & No & 0 \\
\hline CST7 & $\begin{array}{l}\text { A process is in place for collection, recording and analysis } \\
\text { of ADR reports }\end{array}$ & Yes & No & No & No & Yes & Yes & 3 \\
\hline \multirow[t]{5}{*}{ CST8 } & $\begin{array}{l}\text { Incorporation of pharmacovigilance into the orientation } \\
\text { programme curriculum of newly employed health care } \\
\text { professionals }\end{array}$ & No & No & No & No & No & Yes & 1 \\
\hline & CST8a: for Medical doctors & No & No & No & No & No & Yes & 1 \\
\hline & CST8b: for Dentists & No & No & No & No & No & Yes & 1 \\
\hline & CST8c: for Pharmacists & Yes & No & No & Yes & No & Yes & 2 \\
\hline & CST8d: for Nurses/Midwives; & No & No & No & No & No & No & 0 \\
\hline CST9 & $\begin{array}{l}\text { Existence of a newsletter/information bulletin/website } \\
\text { as a tool for Pharmacovigilance information dissemination }\end{array}$ & No & No & No & No & No & Yes & 1 \\
\hline CST10 & $\begin{array}{l}\text { Existence of pharmacovigilance advisory committee or } \\
\text { an expert committee in the setting capable of providing } \\
\text { advice on medicine safety. }\end{array}$ & Yes & No & No & Yes & Yes & Yes & 4 \\
\hline
\end{tabular}

${ }^{a}$ The items in CST6a-e were all considered separately and the answer was found to be No for each item. UBTH University of Benin Teaching Hospital Benin-City, Edo State; UCTH University of Calabar Teaching Hospital, Calabar Cross-River State; UPTH University of Port Harcourt Teaching Hospital, Port Harcourt, Rivers State; UUTH University of Uyo Teaching Hospital, Uyo, Akwa- Ibom State; DELSUTH Delta State University Teaching Hospital Oghara, Delta State; NDUTH Niger Delta University Teaching Hospital Okolobri, Bayelsa State; ADR Adverse Drug Reaction; WHO World Health Organization

Interestingly, one of the centers (DELSUTH) modified the ADR form showing their own hospital logo and domiciling the ADR form to their setting. This showed the willingness of the centre to improve patient safety through a sense of ownership. The inclusion of health facilities in the Nigerian national pharmacovigilance policy was to increase their participation in the pharmacovigilance activities [6]. The study revealed poor budgeting for pharmacovigilance as only a center (UBTH) had financial provision for pharmacovigilance. This was distinct from the finding in Rwanda using the Indicator based pharmacovigilance assessment tool (IPAT) where the hospitals studied had budgetary allocation for pharmacovigilance [31]. The availability of relevant staff and committees are paramount to the development of pharmacovigilance and the hospitals with developed committees and personnel disposition had slightly better reports. It is important to fund pharmacovigilance as development of active pharmacovigilance programs, provision of training, feedback, information dissemination and maintenance of the centers are useful tools in pharmacovigilance that require adequate finances [32]. Capacity development is required for the growth of pharmacovigilance as shown in the review of three countries where insufficient manpower contributed to poor development of pharmacovigilance [27].

The processes and outcomes were however poor in all the facilities probably due to lack of awareness of measuring indices to monitor and evaluate pharmacovigilance. Again, the pharmacovigilance system in this setting is still in their infancy and the requisite culture to ensure effective operations yet to be established. However, it was noted that a cohort event monitoring of antimalarials (artemisinin-based combination therapy) 
Table 3 Analysis of WHO Core Pharmacovigilance Process Indicators of the six tertiary hospitals in the South-South zone of Nigeria

\begin{tabular}{|c|c|c|c|c|c|c|c|}
\hline Indicator Item & Assessment questions & UCTH & UUTH & UPTH & NDUTH & DELSUTH & UBTH \\
\hline$\overline{\mathrm{CP} 1}$ & Total number of ADR reports received in the previous year & 16 & 0 & 0 & 1 & 9 & 26 \\
\hline CP2 & Reports (current total number) in the local database & 41 & 1 & 0 & 12 & 12 & 831 \\
\hline CP3 & Percentage of total annual reports acknowledged/issued feedback & 0 & 0 & 0 & 0 & 0 & 0 \\
\hline CP4 & $\begin{array}{l}\text { Percentage of total reports subjected to causality assessment in } \\
\text { the previous year. }\end{array}$ & 0 & 0 & 0 & 0 & 0 & 84.6 \\
\hline CP5 & $\begin{array}{l}\text { Percentage of total annual reports satisfactorily completed } \\
\text { and submitted to the local Pharmacovigilance Centre in the } \\
\text { previous year. }\end{array}$ & 18.8 & 0 & 0 & 0 & 77.8 & 84.6 \\
\hline CP5a & $\begin{array}{l}\text { Percentage of reports committed to National Pharmacovigilance } \\
\text { Centre database from the local Pharmacovigilance centre }\end{array}$ & 0 & 0 & 0 & 0 & 0 & 100 \\
\hline CP6 & $\begin{array}{l}\text { Percentage of reports of therapeutic ineffectiveness received } \mathrm{i} \\
\mathrm{n} \text { the previous year }\end{array}$ & 0 & 0 & 0 & 0 & 0 & 0 \\
\hline CP7 & $\begin{array}{l}\text { Percentage of reports on medication errors reported in the } \\
\text { previous year }\end{array}$ & 0 & 0 & 0 & 0 & 0 & 7.7 \\
\hline
\end{tabular}

CP8 Percentage of registered pharmaceutical industries having

Only applicable at the level of National Pharmacovigilance Centre a functional Pharmacovigilance system? Not applicable in this study.

CP9 Number of active surveillance activities initiated, ongoing or completed in the last five years

UBTH University of Benin Teaching Hospital Benin-City, Edo State; UCTH University of Calabar Teaching Hospital, Calabar Cross-River State; UPTH University of Port Harcourt Teaching Hospital, Port Harcourt, Rivers State; UUTH University of Uyo Teaching Hospital, Uyo, Akwa- Ibom State; DELSUTH Delta State University Teaching Hospital Oghara, Delta State; NDUTH Niger Delta University Teaching Hospital Okolobri, Bayelsa State; ADR Adverse Drug Reaction; WHO World Health Organization

was conducted in UBTH as a part of a national program. This active surveillance of medicines used in a disease of public health importance is useful in obtaining better insights into the safety and tolerability pattern in our setting [4]. The need for the indicators could also be seen in a review of three national centers India, Uganda and South Africa using the WHO minimum requirements for a functional pharmacovigilance system by Maigetter et al. [27] which suggested a more efficient and systematic monitoring for pharmacovigilance system. An awareness of regular pharmacovigilance evaluations with pharmacovigilance indicators would translate to better pharmacovigilance processes and outcomes.

Table 4 Analysis of WHO Core Outcome Pharmacovigilance Indicators in six tertiary hospitals in South-South zone of Nigeria ${ }^{a}$

\begin{tabular}{|c|c|c|c|c|c|c|c|}
\hline Indicator Item & Assessment questions & UCTH & UUTH & UPTH & NDUTH & DELSUTH & UBTH \\
\hline $\mathrm{CO} 1$ & $\begin{array}{l}\text { Number of signals generated in the } \\
\text { last } 5 \text { years }\end{array}$ & 0 & 0 & 0 & 0 & 0 & $1^{\mathrm{b}}$ \\
\hline $\mathrm{CO} 2$ & $\begin{array}{l}\text { Number of regulatory notifications } \\
\text { issued in the last year }\end{array}$ & 0 & 0 & 0 & 0 & 0 & 0 \\
\hline $\mathrm{CO} 3$ & $\begin{array}{l}\text { Number of medicine-related hospital } \\
\text { admissions per } 1000 \text { admissions } s^{a}\end{array}$ & 1.67 & 1.65 & 0.0985 & 0.3924 & No data & 0.97 \\
\hline $\mathrm{CO} 4$ & $\begin{array}{l}\text { Number of medicine-related deaths } \\
\text { per } 1000 \text { persons served by the } \\
\text { hospital per year }\end{array}$ & $\begin{array}{l}\text { Inadequate } \\
\text { data }\end{array}$ & $\begin{array}{l}\text { Inadequate } \\
\text { data }\end{array}$ & $\begin{array}{l}\text { Inadequate } \\
\text { data }\end{array}$ & $\begin{array}{l}\text { Inadequate } \\
\text { data }\end{array}$ & $\begin{array}{l}\text { Inadequate } \\
\text { data }\end{array}$ & $\begin{array}{l}\text { Inadequate } \\
\text { data }\end{array}$ \\
\hline $\operatorname{co5}$ & $\begin{array}{l}\text { Number of medicine-related deaths } \\
\text { per } 100,000 \text { persons in the population }\end{array}$ & \multicolumn{5}{|c|}{ Only applicable at the level of National Pharmacovigilance Centre } & \\
\hline CO6 & $\begin{array}{l}\text { Average cost (US\$) of treatment } \\
\text { of medicine-related illness }\end{array}$ & $\begin{array}{l}\text { Inadequate } \\
\text { data }\end{array}$ & $\begin{array}{l}\text { Inadequate } \\
\text { data }\end{array}$ & $\begin{array}{l}\text { Inadequate } \\
\text { data }\end{array}$ & $\begin{array}{l}\text { Inadequate } \\
\text { data }\end{array}$ & $\begin{array}{l}\text { Inadequate } \\
\text { data }\end{array}$ & $\begin{array}{l}\text { Inadequate } \\
\text { data }\end{array}$ \\
\hline $\mathrm{CO} 7$ & $\begin{array}{l}\text { Average duration (Days) of medicine- } \\
\text { related extension of hospital stay }\end{array}$ & $\begin{array}{l}\text { Inadequate } \\
\text { data }\end{array}$ & $\begin{array}{l}\text { Inadequate } \\
\text { data }\end{array}$ & $\begin{array}{l}\text { Inadequate } \\
\text { data }\end{array}$ & $\begin{array}{l}\text { Inadequate } \\
\text { data }\end{array}$ & $\begin{array}{l}\text { Inadequate } \\
\text { data }\end{array}$ & 5.86 days \\
\hline CO8 & $\begin{array}{l}\text { Average cost (US\$) of medicine- } \\
\text { related hospitalization. }\end{array}$ & $\begin{array}{l}\text { Inadequate } \\
\text { data }\end{array}$ & $\begin{array}{l}\text { Inadequate } \\
\text { data }\end{array}$ & $\begin{array}{l}\text { Inadequate } \\
\text { data }\end{array}$ & $\begin{array}{l}\text { Inadequate } \\
\text { data }\end{array}$ & $\begin{array}{l}\text { Inadequate } \\
\text { data }\end{array}$ & $\begin{array}{l}\text { Inadequate } \\
\text { data }\end{array}$ \\
\hline
\end{tabular}

${ }^{a}$ Calculated according to data from Table $1,{ }^{b}$ Frequent micturition following use of amlodipine besylate is being evaluated in the centre

UBTH University of Benin Teaching Hospital Benin-City, Edo State; UCTH University of Calabar Teaching Hospital, Calabar Cross-River State, UPTH University of Port Harcourt Teaching Hospital, Port Harcourt, Rivers State; UUTH University of Uyo Teaching Hospital, Uyo, Akwa- Ibom State; DELSUTH Delta State University Teaching Hospital Oghara, Delta State; NDUTH Niger Delta University Teaching Hospital Okolobri, Bayelsa State; ADR Adverse Drug Reaction 
The poor record keeping in all the facilities also made computations of the process and outcomes indicators difficult to achieve. The documentation of medicine related events especially adverse drug reactions were equally poor in this study, this contributed to lack of data even in hospitals where the international coding of diseases was been done. This is not different from what has been reported in other studies about under-recognition of adverse drug reactions and drug related events [33, 34]. It is imperative to inculcate a more articulate approach to routine data gathering and documentation into the healthcare system. Furthermore, planned prospective data collection processes should be put in place to enable evaluation of the outcomes and impact of pharmacovigilance activities.

In the utilization of the WHO pharmacovigilance indicators, it is evident that the scope of reportable incidents by the facilities have been broadened and it is hoped that with the implementation framework of the Nigerian national pharmacovigilance policy, there would be a wider dissemination of the roles that tertiary hospitals are to play in the promotion of pharmacovigilance. The WHO pharmacovigilance indicators would be useful in assessing other tertiary hospitals as it would enable the hospital management develop a strategy towards improving patient safety through pharmacovigilance. It may also help identify areas that need urgent intervention or modification in the health information system management of the tertiary hospitals especially since it is recommended that the indicators be reapplied as needed in the facilities.

\section{Limitations}

The WHO indicators have proven to be quite useful in this assessment. However, absence of trained pharmacovigilance personnel hindered the provision of results for the pharmacovigilance process indicators in the centers. Of note is the limitation of the structural pharmacovigilance indicators to fully capture the functionality of the pharmacovigilance system. Furthermore, the overall poor documentation in all centers limited the derivation of the indicators. Again the derivation of the outcome/impact indicator required in-depth survey which young pharmacovigilance systems are unable to execute. There might be a need to develop a scoring system to quantify the indices thus highlighting the deficiencies in numerical terms.

\section{Conclusion}

This study has shown an urgent need to strengthen the pharmacovigilance systems in the South-South zone of Nigeria. The WHO pharmacovigilance indicators have been proven to be helpful in assessing the pharmacovigilance system in the zone. Improvement in medical record documentation as well as increased institutionalization of pharmacovigilance may be the first steps to improve pharmacovigilance activities in the tertiary hospitals.

\section{Additional file}

Additional file 1: Assessment of the state of Pharmacovigilance in the South-South Zone of Nigeria using WHO Pharmacovigilance indicators. WHO Core Pharmacovigilance Indicators including changes made to phrasing of the assessment questions. (PDF $347 \mathrm{~kb}$ )

\section{Abbreviations \\ ADR: Adverse drug reaction; DELSUTH: Delta State University Teaching Hospital Oghara, Delta State; ICSR: Individual case safety report; IPAT: Indicator based Pharmacovigilance Assessment Tool; NAFDAC: National Agency for Food, Drugs Administration and Control, Nigeria; NDUTH: Niger Delta University Teaching Hospital Okolobri, Bayelsa State; NPC: National Pharmacovigilance Centre; UBTH: University of Benin Teaching Hospital Benin-City, Edo State; UCTH: University of Calabar Teaching Hospital, Calabar Cross-River State; UPTH: University of Port Harcourt Teaching Hospital, Port Harcourt, Rivers State; UUTH: University of Uyo Teaching Hospital, Uyo, Akwa- Ibom State; WHO: World Health Organization}

\section{Acknowledgements}

The authors thank the Chief Medical Directors of the various institutions visited as well as the members of the pharmacovigilance committees, units and staff of the hospitals. We are also grateful to the Director General of the National Agency for Food Drugs Administration and Control (NAFDAC) HQ, Abuja and the South - South Zonal Staff for their kind assistance in carrying out this work.

\section{Funding \\ The study was self funded.}

\section{Availability of data and materials}

The datasets used and/or analysed during the current study are available from the corresponding author on reasonable request.

\section{Authors' contributions}

AOO conceptualised the study, modified the data collection tool, collected and analysed data and wrote the initial manuscript. AFR reviewed the protocol, the data collection tool, analysed the data and revised the manuscript. $\mathrm{AOI}$ was part of the technical team that drafted the $\mathrm{WHO}$ Pharmacovigilance indicators, conceptualised the study, reviewed the study protocol, analysed the data collected and also revised the manuscript. All authors revised and approved the final manuscript.

\section{Ethics approval and consent to participate}

Ethical approval was obtained from the Ethics and research committees of all participating institutions: Delta State University Teaching Hospital Oghara: DELSUTH/HREC/2015/024, Niger Delta University Teaching Hospital Okolobri,: NDUTH/REC/0005/2015, University of Benin Teaching Hospital Benin-City: UBTH:ADM/E22/2NOL.VII/1245, University of Calabar Teaching Hospital, Calabar: UCTH/HREC/33/360, University of Port Harcourt Teaching Hospital, Port Harcourt: UPTH/ADM/90/S.IINOL.X/668 and University of Uyo Teaching Hospital, Uyo: UUTH/AD/S/96/NOL.XIV/357. The heads of the institutions equally gave approval for participation and access to pertinent publicly accessible data; including instructions to the person(s) in charge of pharmacovigilance at the various institutions who then gave verbal consent as approved by the ethics committees. All ethical considerations were duly observed.

\section{Competing interests}

The authors declare that they have no competing interests.

\section{Publisher's Note}

Springer Nature remains neutral with regard to jurisdictional claims in published maps and institutional affiliations.

\section{Author details}

${ }^{1}$ Department of Clinical Pharmacology and Therapeutics, University of Benin, Benin-City, Edo State, Nigeria. ${ }^{2}$ Department of Medicine, University of Benin Teaching Hospital, Benin-City, Nigeria. ${ }^{3}$ Inserm, Bordeaux Population Health 
Research Center, team, Pharmacoepidemiology, University Bordeaux, UMR 1219, F-33000 Bordeaux, France. ${ }^{4}$ Bordeaux PharmacoEpi, INSERM CIC1401, F-33000 Bordeaux, France. ${ }^{5} \mathrm{CHU}$ de Bordeaux, Pôle de santé publique, Service de Pharmacologie médicale, F-33000 Bordeaux, France. ${ }^{6}$ National Drug Safety Advisory Committee, National Agency for Food and Drug Administration and Control, Federal Ministry of Health, Abuja, Nigeria.

Received: 19 January 2018 Accepted: 22 May 2018

Published online: 31 May 2018

\section{References}

1. National Pharmacovigilance Centre (NPC) NAFDAC. Safety of medicines in Nigeria: a guide for detecting and reporting adverse drug reactions. NAFDAC-NPC-NIG Lagos, Nigeria: National Pharmacovigilance Centre (NPC), NAFDAC; 2004 I.

2. Isah A, Olowofela A. Clinical pharmacology in Nigeria: the Benin City experience. Pharmacology matters. 2014;7:11-2.

3. Olowofela A, Fourrier-Réglat A, Isah AO. Pharmacovigilance in Nigeria: an overview. Pharmaceut Med. 2016;30:87-94.

4. Bassi PU, Osakwe Al, Isah A, Suku C, Kalat M, Jalo I, et al. Safety of artemisinin-based combination therapies in Nigeria: a cohort event monitoring study. Drug Saf. 2013;36:747-56.

5. Federal Ministry of Health. National drug policy. Abuja, Nigeria: Federal Ministry of Health; 2005.

6. National Agency for Food and Drug Administration And Control \{NAFDAC\}. National policy and implementation guidleine on pharmacovigilance. Abuja, Nigeria: National Agency for Food and Drug Administration And Control; 2012.

7. National Agency for Food and Drug Administration And Control \{NAFDAC\}. Directorates. 2013. http:/www.nafdac.gov.ng/index.php/about-nafdac/ directorates/pharmacovigilance-post-marketing-surveilance. Accessed 29 May 2014.

8. Oshikoya KA, Senbanjo IO, Njokanma OF. Parental reporting of suspected adverse drug reactions in children in Lagos, Nigeria. Arch Dis Child. 2009;94: 469-73.

9. Isah AO. Drug safety in emerging countries-a perspective from Nigeria. Clin Ther. 2013;35:e118.

10. Olowofela A, Isah AO. A profile of adverse effects of antihypertensive medicines in a tertiary care clinic in Nigeria. Ann Afr Med. 2017;16:114-9.

11. Ogunleye OO, Oreagba IA, Falade C, Isah A, Enwere O, Olayemi S, et al. Medication errors among health professionals in Nigeria: a national survey. Int J Risk Saf Med. 2016;28:77-91.

12. Okuonghae HO, Ighogboja IS, Lawson JO, Nwana EJ. Diethylene glycol poisoning in Nigerian children. Ann Trop Paediatr. 1992;12:235-8.

13. Ugwu GMI, Okperi BO, Ugwu EN, Okolugbo N. Childhood poisoning in Warri, Niger Delta, Nigeria: a ten year retrospective study. African J Prm Health Care Fam Med. 2012;4 http://www.phcfm.org/index.php/phcfm/ article/view/321/406. Accessed 29 May 2018.

14. Moride Y, Haramburu F, Requejo AA, Bégaud B. Under-reporting of adverse drug reactions in general practice. Br J Clin Pharmacol. 1997;43:177-81.

15. Pushkin R, Frassetto L, Tsourounis C, Segal E, Kim S. Improving the reporting of adverse drug reactions in the hospital setting. Postgrad Med. 2010;122: 154-64.

16. Isah AO, Pal SN, Olsson S, Dodoo A. Specific features of medicines safety and pharmacovigilance in Africa. Ther Adv Drug Safety. 2012;3:25-34.

17. Ogundele S, Dawodu C, Ogunleye O. Adverse drug reaction reporting among healthcare workers at a Nigerian tertiary hospital: a comparative cross-sectional survey of health care professionals. Glob. Res J Med Sci. 2012;2:32-7.

18. Oreagba A, Ogunleye O, Olayemi S. The knowledge, perceptions and practice of pharmacovigilance amongst community pharmacists in Lagos state, south West Nigeria. Pharmacoepidemiol Drug Saf. 2011;20:30-5.

19. Chinenye JU, Michael OU. Health workers and hospital patients knowledge of pharmacovigilance in Sokoto, north-West Nigeria. Niger J Pharm Sci. 2012;11:31-40

20. Bello SO, Umar MT. Knowledge and attitudes of physicians relating to reporting of adverse drug reactions in Sokoto, North-Western Nigeria. Ann Afr Med. 2011;10:13-8.

21. Oshikoya KA, Awobusuyi JO. Perceptions of doctors to adverse drug reaction reporting in a teaching hospital in Lagos, Nigeria. BMC Clin Pharmacol. 2009;9:14.
22. Fadare JO, Enwere OO, Afolabi AO, Chedi BAZ, Musa A. Knowledge, attitude and practice of adverse drug reaction reporting among healthcare workers in a tertiary Centre in northern Nigeria. Trop J Pharm Res. 2011;10:235-42.

23. Ali Saleh $\mathrm{H}$, Fiqueras A, Fourrier-Réglat A. Knowledge, attitude and practice of health professionals towards adverse drug reactions reporting. Eur J Pharm Med Res. 2016;3:12-21.

24. World Health Organization. Safety monitoring of medicinal products: guidelines for setting up and running a pharmacovigilance Centre. Uppsala, Sweden: the Uppsala monitoring Centre (the UMC). In: WHO collaborating Centre for International Drug Monitoring; 2000.

25. Begaud B. Pharmacovigilance in France: a decentralized approach. In: Strom $B L$, Velo G, editors. Drug epidemiology and post-marketing surveillance. Boston, MA: Springer US; 1992. p. 39-42.

26. Kalaiselvan $V$, Thota P, Singh GN. Pharmacovigilance Programme of India: recent developments and future perspectives. Indian J Pharmacol. 2016:48:624-8.

27. Maigetter K, Pollock AM, Kadam A, Ward K, Weiss MG. Pharmacovigilance in India, Uganda and South Africa with reference to WHO's minimum requirements. Int J Heal policy Manag. 2015;4:295-305.

28. Strengthening Pharmaceutical Systems (SPS) Program. Safety of Medicines in Sub-Saharan Africa. Assessment of pharmacovigilance systems and their performance. Arlington VA: US Agency for international development; 2011.

29. World Health Organization. WHO pharmacovigilance indicators: A practical manual for the assessment of pharmacovigilance systems WHO. Geneva: World Health Organisation; 2015.

30. Vallano A, Cereza G, Pedròs C, Agustí A, Danés I, Aguilera C, et al. Obstacles and solutions for spontaneous reporting of adverse drug reactions in the hospital. Br J Clin Pharmacol. 2005;60:653-8.

31. Kabore L, Millet P, Fofana S, Berdai D, Adam C, Haramburu F. Pharmacovigilance systems in developing countries: an evaluative case study in Burkina Faso. Drug Saf. 2013;36:349-58.

32. Pimpinella G, Tartaglia L. Pharmacovigilance and the Italian medicines agency. J Pharmacol Pharmacother. 2013;4(Suppl 1):S4-6.

33. Hazell L, Shakir SA. Under-reporting of adverse drug reactions: a systematic review. Drug Saf. 2006;29:385-96.

34. Lopez-Gonzalez E, Herdeiro M, Figueiras A. Determinants of under-reporting of adverse drug reactions. A systematic review. Drug Saf. 2009;32:19-31.

\section{Ready to submit your research? Choose BMC and benefit from:}

- fast, convenient online submission

- thorough peer review by experienced researchers in your field

- rapid publication on acceptance

- support for research data, including large and complex data types

- gold Open Access which fosters wider collaboration and increased citations

- maximum visibility for your research: over $100 \mathrm{M}$ website views per year

At BMC, research is always in progress.

Learn more biomedcentral.com/submissions 